\title{
Los conjuntos habitacionales en los procesos de "integración socio-urbana": los casos de Playón de Chacarita y barrio Padre Carlos Mugica
}

\begin{abstract}
Sandra Inés Sánchez
Investigadora del CONICET clase independiente con sede en el Instituto Superior de Urbanismo, Territorio y el Ambiente de la Facultad de Arquitectura, Diseño y Urbanismo de la Universidad de Buenos Aires. Profesora adjunta en la materia Historia en la misma casa de estudios. Integra el equipo de investigadores del Programa Interdisciplinario de la UBA sobre Marginaciones Sociales (PIUBAMAS). Integrante del Movimiento Popular La Dignidad. sandrainesanchez@gmail.com.

\section{Jonatan Emanuel Baldiviezo}

Presidente del Observatorio del Derecho a la Ciudad. Fundador de la Asociación por la Justicia Ambiental. Integrante del Movimiento Popular La Dignidad. Abogado en cuestiones de Derechos Humanos y derechos urbanos y ambientales. Investigador en el Instituto Superior de Urbanismo, Territorio y el Ambiente de la Facultad de Arquitectura, Diseño y Urbanismo de la Universidad de Buenos Aires. Integra el equipo de investigadores del Programa Interdisciplinario de la UBA sobre Marginaciones Sociales (PIUBAMAS).

jonatan.baldiviezo@gmail.com.
\end{abstract}

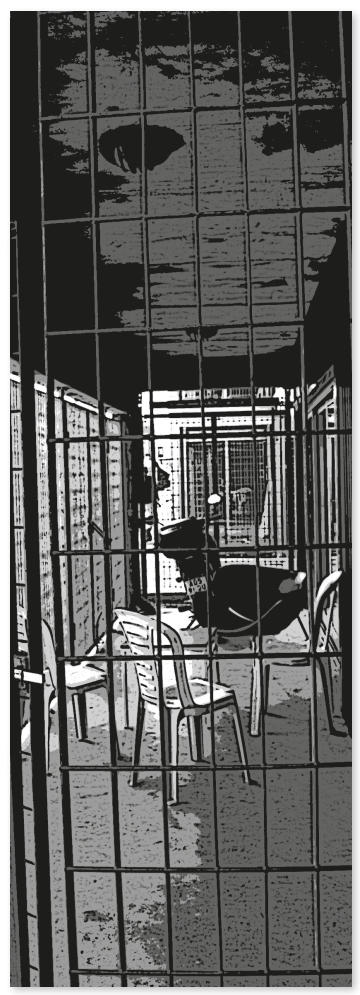

http://dx.doi.org/10.30972/crn.26263830 ISNN 1666-6186. Volumen 26 N. ${ }^{\circ} 26$ (Junio de 2019) Pp. 153-185 - Recibido: 20-09-18. Aprobado: 29-05-19 


\section{Los conjuntos habitacionales en los procesos de "integración socio-urbana": los casos de Playón de Chacarita y barrio Padre Carlos Mugica}

\section{Resumen}

Se propone el análisis de los conjuntos habitacionales en el contexto de los actuales procesos de "integración socio-urbana” llevados adelante por el gobierno de la Ciudad de Buenos Aires en dos villas: el barrio Padre Carlos Mugica (ex villas 31 y 31 bis) y Playón de Chacarita. Se indagará en el rol de los conjuntos habitacionales en las políticas de "integración socio-urbana” y su tratamiento, significaciones y simbolizaciones en los procesos participativos y en las acciones de gobierno. Se persigue evaluar la índole de los procesos en curso, con la finalidad de desentrañar las consistencias e inconsistencias en el orden del derecho a la ciudad y la vivienda, conforme están establecidos en los instrumentos constitucionales de la nación y la ciudad.

\section{Palabras clave}

Villas; integración socio-urbana; conjuntos habitacionales.

\section{The housing complexes in the processes of "socio- urban integration": the case of Playón de Chacarita and Barrio Padre Carlos Mugica}

\section{Abstract}

The analysis of the housing complexes is proposed in the context of the current processes of "socio-urban integration" carried out by the government of the City of Buenos Aires in two informal settlements: Barrio Padre Carlos Mugica (ex Villas 31 and 31 bis) and Playón de Chacarita. It will be inquired into the role of the housing complexes in the "socio-urban integration" policies, and their treatment, meanings and symbolizations in participatory processes and government actions. The aim is to evaluate the nature of the processes in progress, with the purpose of unraveling the consistencies and inconsistencies in the order of the right to the city and housing as they are established in the constitutional instruments of the nation and the city.

\section{Keywords}

Informal settlements; socio-urban integration; housing complexes

\section{Os conjuntos habitacionais nos processos de "integração sócio urbana": os casos do Playón de Chacarita e Barrio Padre Carlos Mugica}

\section{Resumo}

É proposta a análise dos conjuntos habitacionais no contexto dos atuais processos de "integração sócio urbana” realizados pelo governo da Cidade de Buenos Aires em dois vilas: o Bairro Padre Carlos Mugica (ex Villas 31 e 31 bis) e o Playón de Chacarita. Será indagado o papel dos conjuntos habitacionais nas políticas de "integração sócio-urbana”, e seu tratamento, significados e simbolizações em processos participativos e ações governamentais serão investigados. O objetivo é avaliar a natureza dos processos em andamento, com o objetivo de desvendar as consistências e inconsistências na ordem do direito à cidade e à habitação, conforme estão estabelecidos nos instrumentos constitucionais da nação e da cidade.

\section{Palavras chave}

Vilas; integração sócio urbana; conjuntos habitacionais 


\section{Introducción ${ }^{1}$}

En el año 2016, durante la gestión de Rodríguez Larreta como jefe de gobierno, se lanzó un plan de inversión de 7069 millones de pesos en diferentes "líneas de acción" destinadas a la "integración socio-urbana" de cinco villas de la ciudad: barrio Padre Carlos Mugica ${ }^{2}$ (ex villas 31 y 31 bis), villa 20, Rodrigo Bueno, Lamadrid y Playón de Chacarita. ${ }^{3}$ En líneas generales, desde el punto de vista de la planificación y el diseño urbano, el proceso de integración socio-urbana implica apertura y tendido de redes viarias y de infraestructura urbana, "mejoramiento" de las viviendas existentes, "esponjamiento" del tejido a los efectos de garantizar accesibilidad y condiciones de iluminación, ventilación y salubridad y construcción de conjuntos habitacionales destinados a los habitantes que van a ser relocalizados. Todas estas cuestiones se tratan en mesas participativas con múltiples actores involucrados: habitantes, el Instituto de la Vivienda (IVC), la Defensoría General de la Ciudad de Buenos Aires (DG), la Defensoría del Pueblo (DP) y representantes del ámbito legislativo, conformados en diferentes grupos y sectores sociales, político-partidarios y multisectoriales que ponen en confrontación retóricas, acciones, significaciones y simbolizaciones en torno al proceso de "integración socio-urbana”.

El concepto de "integración socio-urbana" acuñado desde el gobierno implica un cambio en la significación de la cuestión de las villas, basado en la consideración de los procesos de segregación como fenómenos sociales complejos por la vulneración de múltiples derechos que conllevan (de acceso a la justicia, laborales, de salud, educación, accesibilidad, entre otros). Pero este tipo de abordaje requiere intervenciones multiescalares de gestión y acción, que deben a su vez implementarse, de acuerdo con la Constitución, a través de procesos participativos.

El plan de "integración socio-urbana" de Rodríguez Larreta emerge de una política urbana de gobierno que fomenta la venta de tierras públicas, y que junto con la reformulación del código urbanístico y de edificación fue
1. Este trabajo se realizó en el marco de los siguientes proyectos subsidiados: UBACyTModalidad I 20020150100191BA: "Derecho y justicia en las problemáticas habitacionales: el rol de las instituciones y las organizaciones sociales", con sede en el ISU/FADU/UBA (directores: Sandra Inés Sánchez y Rodrigo Amuchástegui), programación científica 2016-2018 (1/1/2016-31/12/2017); UBACYT Interdisciplinario 20620160100005BA, Área Marginaciones Sociales PIUBAMAS: "Espacio social y políticas públicas de acceso a la tierra y la vivienda en Buenos Aires en perspectiva histórica", con sede en la Sección de Antropología Social; Instituto de Ciencias Antropológicas, Facultad de Filosofía y Letras de la Universidad de Buenos Aires (directoras: Claudia Fabiana Guebel y Sandra Inés Sánchez); programación científica 2017-2019 (1/1/2017-31/12/2019) y el Proyecto CONICET Intersubjetividades en el espacio doméstico en la Ciudad de Buenos Aires en dos escenarios históricos (2017-2018).

Los autores, desde el Observatorio del Derecho a la Ciudad y la Facultad de Arquitectura, Diseño y Urbanismo de la Universidad de Buenos Aires, desde 2016 participan como asesores técnicos en la Mesa de Gestión Participativa de Playón de Chacarita, y participaron desde 2017 en los procesos de debate de elaboración del Dictamen de la Ley 3343 del Barrio Padre Carlos Mugica. La participación en los procesos participativos de formulación de leyes de villas de BALDIVIEZO tiene larga data y comenzó con un rol activo en la redacción de la primera de las leyes, la Ley 3343 de la entonces villa 31.

\section{En adelante barrio Mugica.}

3. En adelante Playón. 


\section{La cursiva es nuestra.}

5. El $67 \%$ de las viviendas están sobre pasillos; el $90 \%$

tiene acceso al agua de sus viviendas por red informal; el $97 \%$ no tiene red de gas; el 92

$\%$ tiene acceso a red cloacal informal; el $90 \%$ tiene acceso a la red eléctrica sin medidor. caracterizando a Buenos Aires como una ciudad de los negocios con obra pública y "de los promotores inmobiliarios"4 (HALL, 1996: 354-372). El abordaje de la villa 20 quedó estrechamente relacionado con la re-urbanización del Parque de la Ciudad y la construcción de la villa Olímpica, cuya ley autorizaba la venta de aproximadamente 40 hectáreas del parque público con la excusa de que el $50 \%$ de los ingresos de la venta debía ser destinado a la urbanización de dicha villa.

El Proyecto Urbano del Barrio Mugica se concentró en el desplazamiento de la traza de la autopista Illia y la generación de un paseo elevado a la manera del neoyorquino High Line Park como primer paso del proceso, y que iba a insumir un tercio del presupuesto destinado a la urbanización. En la villa Rodrigo Bueno la finalidad consistía en destrabar el más importante emprendimiento inmobiliario de IRSA en la ciudad, una suerte de gran Dubai argentina en los terrenos de la ex Ciudad Deportiva de La Boca, en donde se montarían los "Solares de Santa María". En Playón los primeros anuncios del proceso de integración socio-urbana fueron sobre la apertura de la avenida Triunvirato, y las primeras acciones se concentraron en la relocalización de los desalojados con motivo de la nueva traza, para la que hubo que implementar una línea especial de créditos subsidiados en un $40 \%$, y con condiciones más favorables que la Ley 341.

En el año 2016, también se promovía otro gran emprendimiento inmobiliario validado estratégicamente con la creación del Parque de la Innovación en los predios del ex Tiro Federal, cuya Ley 5558 que autorizaba la venta de las 17 hectáreas para la creación de este parque destinaba a la urbanización del barrio Mugica el 20 \% de lo producido de la venta del polígono más valorizado. Se vendían tierras públicas recurriendo a la urbanización para que esta fuera posible.

En Playón viven de 2764 personas que representan 1042 familias con un total de 513 viviendas (GCBA, 2018). ${ }^{5}$ El proyecto habitacional implica la mejora de cerca de 300 viviendas “que quedarán en el sector histórico del barrio", y la construcción de conjuntos habitacionales para las relocalizaciones con una cantidad de cerca de 670 viviendas. En el barrio Mugica se calcula que viven cerca de 60.000 personas, conformadas en 10.400 hogares en un predio de 46 hectáreas (GCBA, 2018b), y los complejos habitacionales recientes tienen un total aproximado de 1300 viviendas. Ambas villas se encuentran localizadas en zonas altamente valorizadas de la ciudad. 
Se propone el análisis de los conjuntos habitacionales en el contexto de los actuales procesos de "integración socio-urbana" llevados adelante por el gobierno de la Ciudad de Buenos Aires en dos villas: el barrio Mugica (ex villas 31 y 31 bis) y Playón. Se indagará en el rol de los conjuntos habitacionales en las políticas de "integración socio-urbana" y su tratamiento, significaciones y simbolizaciones en los procesos participativos y en las acciones de gobierno. Se persigue evaluar la índole de los procesos en curso, con la finalidad de desentrañar las consistencias e inconsistencias en el orden del derecho a la ciudad y la vivienda conforme están establecidos en los instrumentos constitucionales de la nación y la ciudad.

El énfasis en la vivienda o en el hábitat indica la caracterización polarizada que ha signado las políticas públicas. Los enfoques "viviendistas" y los más integrales y urbanos marcaron los debates clásicos del problema de la vivienda, la cuestión urbana y las teorías de la ciudad latinoamericana, si bien en las "políticas habitacionales" pervive el sesgo "viviendista" (Del Río 2015 ).

El paradigma del Derecho a la Ciudad constituye un marco político-filosófico acerca de cómo percibir, pensar y comprender la ciudad y los procesos urbanos y de urbanización, y acerca de cómo orientar las voluntades de transformación. Este origen, que tiene como primer referente a HENRI LEFEBVRE, derivó en múltiples concepciones cambiantes en cada escenario histórico, geográfico y político. Tanto Henri Lefebvre como David Harvey inscribieron la afirmación y reivindicación del "derecho a la ciudad" en un combate a la vez teórico y práctico que debía desarrollarse "contra la urbanización capitalista" y "contra el modo de producción” que esta perpetúa (GARNIER, 2012: 218). En el año 1968, sobre la base de la crítica al urbanismo moderno derivado de la Carta de Atenas, Lefebvre describió el "derecho a la ciudad" como un "derecho a la vida urbana, transformada, renovada", en directa relación con las necesidades, aspiraciones y deseos de los habitantes. En sus concepciones, las cuestiones de urbanismo, al concernirle a toda la sociedad, no podían ser tratadas exclusivamente por expertos (1968 [1973: 138, 15]).

Soja propuso un método de acción social y política para mejorar "la equidad y el acceso a los derechos inherentemente urbanos de los ciudadanos", y representó un giro conceptual en el paradigma del "derecho a la ciudad" en relación con la justicia, por abordar de manera transdisciplinaria la relación entre justicia y espacio (BorRA, 2014: 11). En este sentido, se retoman estos autores para tratar de comprender los problemas frecuentes en las 
sociedades relativos al uso y acceso inequitativos del espacio, los recursos e infraestructuras. Se pretende responder a los siguientes interrogantes: ¿en qué medida los procesos urbanos abordados en las villas por el gobierno superan los procesos históricos de segregación urbana?; ¿responden estos procesos a los derechos, necesidades y expectativas de los grupos poblacionales afectados?

Como señala David HaRveY, "vivimos en una época en la que los derechos humanos se han situado en primer plano como modelo político y ético", y si bien se dedica una ingente energía a su "promoción, protección, y articulación" como pilares de transformación de un orden injusto, estos se formulan en "términos individualistas y basados en la propiedad" sin cuestionar "la lógica del mercado liberal y neoliberal hegemónica ni los tipos neoliberales de legalidad y acción estatal” (Harvey, 2012: 19).

Los conceptos de integración, marginación y desigualdad urbana y las nuevas formas que adquiere la pobreza y las formas socio-espaciales de la exclusión y la marginalidad en las grandes ciudades han sido abordados por WACQUANT, quien señala que la marginalidad adopta múltiples formas y modalidades en los diferentes escenarios y contextos $(2001,2007)$.

Se pretende analizar en el contexto de estas políticas cómo la perspectiva de derechos atraviesa el espacio social, cómo este espacio se constituye y es constituido por estas prácticas institucionales y cómo estas prácticas colisionan con la producción social del espacio, histórica, por parte de los mismos habitantes y grupos afectados, pues —en términos de LEFEBVRE- el espacio social "permite que tengan lugar determinadas acciones, sugiere unas y prohíbe otras... e implica múltiples conocimientos” (2013: 129). En resonancia con Dussel, se aborda la transformación de los problemas que afectan a las víctimas del orden económico, político, social y cultural vigente, de aquellos cuyos derechos habitacionales se encuentran vulnerados y siguen vulnerándose desde las políticas de Estado (2006). Se pretende poner en crisis cómo desde el campo disciplinar de la arquitectura y el urbanismo la solución radica en la implementación de métodos "de fabricación de espacios ideales donde por fin..." los habitantes "puedan insertarse plenamente en su medio urbano" (De Certeau, 1994 [2006: 5].

Se parte de una investigación aplicada, del involucramiento de los investigadores en los procesos de integración socio-urbana como asesores técnicos de los habitantes. La investigación 
desarrollada es cualitativa e inductiva. Se desarrollaron conceptos, intelecciones y comprensiones partiendo del trabajo de campo de tipo etnográfico. El método antropológico-etnográfico consiste en una metodología cualitativa de recolección de información de primera mano, mediante la realización de un trabajo de campo, con entrevistas abiertas o cerradas y observación participante. En la etnografía, el investigador participa de la vida cotidiana de personas durante un tiempo relativamente extenso, viendo lo que pasa, escuchando lo que se dice, interrogando e interrogándose; o sea, recogiendo todo tipo de datos accesibles para poder arrojar luz sobre los temas que se estudian (Hammersley y Atkinson, 1994). En líneas generales, la técnica consiste en el relevamiento de datos y de discursos, en la observación sistemática y controlada de todo lo acontecido en los contextos participativos y en todas las actividades relacionadas con el reclamo de derechos habitacionales y en la participación. Como señala GuBER, la "participación” pone el énfasis en la experiencia vivida por el investigador, apuntando su objetivo a "estar adentro" de la sociedad estudiada (2004). Los textos producidos son a su vez analizados con diferentes técnicas y métodos de análisis del discurso. La aplicación de técnicas de "análisis del discurso" busca "despojar al sujeto hablante de su papel central para integrarlo al funcionamiento de enunciados, de textos cuyas condiciones de posibilidad se articulan sistemáticamente sobre formaciones ideológicas” (Maingueneau, 1989 [1976: 10]).

\section{Los procesos en las villas en perspectiva histórica}

Históricamente, el concepto de "urbanización" aplicado a las villas significó su concepción como fuera del espacio urbano de la ciudad, y conllevó su abordaje desde la provisión y regularización de los servicios y redes de infraestructura urbana, como características esenciales de dicho proceso de urbanización. En la articulación entre las retóricas y las acciones de gobierno, las diferentes modalidades de abordaje de las villas fueron desde la refacción, reconstrucción total de las viviendas y su reemplazo por nuevas, hasta la relocalización.

A mediados del año 2008, durante la gestión de Mauricio Macri como jefe de gobierno de la ciudad, se planteó la posibilidad de llamar a un plebiscito sobre un nuevo proyecto de "urbanización" de villas. El tema de consulta era sobre el financiamiento de las "tareas de urbanización”, y planteaba como dos modalidades de gestión del presupuesto el aumento de los impuestos de la ciudad o la postergación obras "de la ciudad" con el consecuente direccionamiento de esos fondos hacia las villas (NAVIA y CASTRo, 2008). 
La identificación de este proyecto como de "urbanización” implicaba desestimar los procesos de urbanización auto-gestionados por los habitantes, a la vez que introducía una nueva lógica de ejecución presupuestaria que confrontaba a las villas, que estaban por fuera del universo de la ciudad, con lo que se concebía como la ciudad propiamente dicha. En el universo simbólico del gobierno el abordaje económico de ambos sub-espacios -y su coexistencia - era inconciliable. Debía optarse por una de ellas: villas o ciudad. Simultáneamente, el entonces jefe de gabinete Horacio Rodríguez Larreta planteaba que no había "recetas únicas" para solucionar el tema de las villas. Según su criterio, las que se encontraban "sobre el Riachuelo" debían erradicarse; incluso llegó a afirmar que "la gente” no podía "vivir un minuto más ahí". También relativizaba la situación respecto de "otros casos”, que sí se podían "urbanizar", debido a que en su concepción las recetas no eran únicas "sobre erradicar o no" (NAVIA y CASTRO, 2008).

Entretanto, el jefe de gobierno, Macri, transparentaba su voluntad de erradicar las villas 31 y 31 bis. Para él era un proceso que debía realizarse "de a poco, mediante el diálogo con la gente, y con el compromiso de darles vivienda en otro lugar". Dentro de esta lógica, la villa 31 no se podía urbanizar "por el peligro de su ubicación" y porque se trataba "de un lugar insalubre". Paradójicamente, se trata de un "lugar" altamente codiciado, con las tierras más valorizadas de la ciudad, que se encontraban y se encuentran en la mira de los capitales inmobiliarios que necesitan ampliar la zona de influencia de Puerto Madero, entre otras tantas cuestiones. Otra posibilidad que evaluaba el mismo Macri en ese momento era "mandar a los inspectores a verificar construcciones peligrosas en altura", que aparecían "todos los días" en las villas, como una manera de poner freno a su crecimiento; pero en un reportaje comentó luego que no lo hacía porque carecía "del poder de policía para ordenar el desalojo" (LN, 2008).

Con este fin, en la anterior gestión de gobierno, a comienzos del año 2007, AUSA había construido un muro con bloques premoldeados para evitar que los habitantes de la villa levantaran "nuevas casillas al costado de la cinta asfáltica". El entonces titular del IVC afirmaba que "la solución para la Villa 31 y la 31 bis" era "la reubicación de los pobladores, mediante un acuerdo entre los gobiernos porteño y nacional” (LN, 2007).

Difícilmente se vislumbraba una intención política de abordaje de las villas con criterios de integración o radicación definitiva, pues la voluntad de relocalizarlas ha trascendido 
todas las gestiones, pero en ese escenario de inicios del PRO en el gobierno, se articuló una inflexión en la índole de los reclamos por parte de los habitantes de la entonces villas 31 y 31 bis. Mientras los gobiernos de ciudad y nación se disputaban responsabilidades por la urbanización de estas tierras que eran de dominio nacional, los reclamos no fueron solo por los servicios de infraestructura urbana, sino también por una urbanización integral. ${ }^{6}$

En un contexto de políticas de Estado gestadas desde la omisión (OszLaK, 1981: 25), en tanto ni desde ciudad ni desde nación se asumían las responsabilidades jurisdiccionales de estos territorios, a comienzos del año 2009 se arribó a un acuerdo de freno a las nuevas construcciones en las villas asentadas en tierras de los ferrocarriles, ${ }^{7}$ y en medio de fuertes reclamos con cortes de la autopista, comenzó a formularse participativamente la primera ley de villas.

Los primeros abordajes en las villas durante la gestión de Macri adoptaron el modelo del peruano Hernando de Soto, que en el año 2000 planteó como centralidad de la política de urbanización y como opción de salida a la pobreza la regularización dominial a través de la entrega de títulos de propiedad. La finalidad última era que los habitantes pudieran "vender", "comprar" y comenzar a "pagar impuestos". En el universo simbólico del gobierno, "darles la escritura" significaba convertirlos "en ciudadanos", y ese "sentido de propiedad" capitalista haría que "la gente" tendiera a "mejorar y fortalecer su propia casa" (Perfil, 2010). Para operativizar este abordaje, en el año 2010 los diputados Enzo Pagani y Cristian Ritondo presentaron un proyecto a la Legislatura de la ciudad que tenía por objeto deslindar la obligación del Poder Ejecutivo de presentar un "plan de urbanización" para cada una de las villas como condición previa para avanzar con la escrituración de las tierras, aunque no prosperó. ${ }^{8}$ Bajo la retórica institucional de "regularización", se evidenciaba la posibilidad de liberar los territorios de las villas a las lógicas del mercado inmobiliario; ${ }^{9}$ finalidad última que atravesaría las intervenciones institucionales de la gestión PRO, desde entonces.

Hasta el año 2016, sobre este sustrato de retóricas y acciones de gobierno, en las villas solo se avanzó en la atención de las emergencias y con intervenciones parciales en el espacio público a la manera de las aplicadas en la ciudad de Medellín, a través de la gestión de la Unidad de Gestión e Intervención Social (UGIS) y la Secretaría de Hábitat e Inclusión (SECHI).
6. En el año 2008, los habitantes reclamaron participar en la audiencia con los representantes de los gobiernos de ciudady nación, según la medida cautelar que ordenaba al gobierno nacional a arbitrar "los medios necesarios para impedir la prosecución de nuevas construcciones" (DG, 2008).

7. Los inspectores debían discernir sobre el ingreso de materiales (T, 2009). En el año 2016 se instrumentó a través de permisos (IP, 2016).

8. El Proyecto de Ley 3325-D2010 fue retirado del temario debido a la oposición de varios bloques y habitantes de las villas. El objetivo principal consistía en quitar responsabilidades al Estado respecto de las obligaciones de brindar servicios públicos, equipamiento y mejorar la situación habitacional de los "inquilinos" (TARBUCH Y BALDIVIEZO, 2014).

9. Ver BALDIVIEZo, 2014, 2016 TARBUCH, 2014. 
La UGIS se creó en el año 2008, para atender las emergencias de infraestructura. Tres años después, en 2011, la creación de la SECHI se orientó a "la búsqueda de soluciones para los grandes problemas de nuestras villas, asentamientos y complejos habitacionales, con una función articuladora e integradora de las políticas y programas de gobierno en la zona Sur" (MACRi, 2016: 10). Según Rodríguez Larreta, esta secretaría se convirtió en una "herramienta fundamental" de "acercamiento a sectores donde existía poca presencia institucional permanente” (MACRI, 2016: 12).

La SECHI fue estratégica en el abordaje de algunas transformaciones claves en el espacio público que en muy contadas excepciones se desprendían de las demandas de cada barrio, como la remodelación de plazas, canchas para deportes y situaciones de emergencia de infraestructuras. A través de lo que denominaron Proyectos Urbanos Integrales, se inauguraba un contacto personalizado con los representantes en las diferentes villas, que como modelo de gestión consolidó el drenaje de recursos como una modalidad de generación de vínculos clientelares.

\section{La cuestión participativa}

La cuestión participativa aparece en la Constitución de la Ciudad de Buenos Aires desde el artículo 1, en el que se establece que la ciudad "organiza sus instituciones autónomas como democracia participativa" y la atraviesa. Este planteo no está exento de conflictos y se desprende de lo que algunos llaman el "nuevo espíritu de la democracia", y que surge de la "pérdida de confianza en los actores que tradicionalmente funcionaron como intermediarios entre el pueblo y sus representantes: partidos, sindicatos, periodistas, expertos". Mientras los "ciudadanos de las democracias contemporáneas no aceptan ya permanecer en silencio entre elección y elección”, "los gobernantes" entienden a su vez que "la escucha" se ha transformado en una "figura obligada de toda acción política y de todo gobierno" (Blondiaux, 2008: 13) como medio de legitimación de lo actuado. En este contexto de crisis de los conceptos de democracia representativa, y participativa, entendida en términos deliberativos y decisionales, se han desplegado los procesos de integración socio-urbana de las villas promovidos por el gobierno.

La definición de las condiciones de participación fue y sigue siendo un aspecto nodal de los reclamos de los habitantes de las villas y de las organizaciones sociales y políticas en cada 
villa. Fallas en la comunicación, insuficiente información y problemas de coordinación en los procesos participativos son algunas cuestiones claves que conspiraron y conspiran en contra de la voluntad participativa y decisional de los habitantes.

La Ley 5705 de la villa 20 fue la primera en sancionarse, y surgió como producto de once años de lucha y reclamos de los vecinos por el cumplimiento de la Ley 1770 (11/08/2005), que disponía la urbanización de la villa, y antes aún, desde fines de la década del 90, con la Ley 148, que establecía su "atención prioritaria”. Los hechos de represión de los años 2010 y 2014 en las tomas del Parque Indoamericano y del predio Papa Francisco signaron los reclamos de urbanización como urgentes, pero fue solo a partir del proyecto de la villa Olímpica que comenzó una nueva etapa de gestión en la Comuna 8 y en la villa.

Desde el año 2015, los procesos de formulación de cada una de las leyes en cada villa corrieron por canales relativamente independientes, y en términos comparativos, significaron inequidades en materia de derechos de unas leyes respecto de otras. Si bien, como señala un habitante, hay "pocas cosas" que unen a las villas y "cada una es particular" (MARTínez, 2016: 22), en los procesos de formulación de las leyes se evidenció cierta asimilación de las cuestiones nodales, que generó un sustrato experiencial que acumulativamente abonó un piso de derechos que se capitalizaba para todos. Entretanto, desde el gobierno la finalidad última consistió en rentabilizar las debilidades dentro del espacio social de los habitantes a favor del gobierno. Tal como señaló otro habitante:

... sabemos que hay muchas villas en las que también se quiere llevar un proceso de urbanización. Justamente, no queremos que nuestra ley sea un copy paste que se aplique en todas las villas, porque entendemos que cada una tiene sus propias problemáticas (SIERRA, 2016: 35).

Aún en este escenario inicial del año 2016, en el que cada villa pugnaba por la especificidad de los procesos, así y todo, se organizaron instancias masivas de intercambio de experiencias. El "Acuerdo por la Urbanización de las Villas" (presentado el 11/10/2016) significó una instancia de organización multisectorial en la que participaron habitantes de las diferentes villas, organizaciones sociales y políticas, asociaciones civiles como la Asociación Civil por la Igualdad y la Justicia y universidades (ACIJ, 2016). Este acuerdo perseguía orientar los procesos de urbanización en las diferentes etapas desde una perspectiva de derechos. 
Las diferentes organizaciones sociales, políticas, de habitantes y las diferentes mesas de urbanización también buscaron en esta instancia inicial nuevos espacios de debate, a la vez que reclamaban participación en los procesos en curso. El 1. ${ }^{\text {er }}$ Encuentro: Debatir y organizarnos por una re-urbanización integral de todas las villas de la ciudad (29/10/2016), promovido desde la Comuna 8, estuvo destinado a todos los que integraban las distintas "Mesas de Urbanización" de las villas de la ciudad, para intercambiar experiencias en torno a estos procesos. Pero sobrevolaba un imaginario de sobrevalorización del poder de negociación de algunas villas por sobre otras, que finalmente fue afectando la posibilidad de un posicionamiento común, y que se replicó en el interior de cada villa. Esto fue minando también la capacidad de negociación y decisional de los habitantes en el interior de cada villa. La política de integración socio-urbana resultó heterogénea, y se fue ajustando en cada caso en función de los objetivos y características de la integración que pretendía el gobierno, y en función también de los tiempos políticos que el gobierno imponía a cada proceso.

Independientemente de estas diferencias nodales, una cuestión clave que resolver en todas las villas fue y sigue siendo el relevamiento censal de los inquilinos, porque en general los propietarios impiden censarlos y quedan excluidos del padrón de beneficiarios de una solución habitacional definitiva enmarcada por ley. Este fue uno de los reclamos más recurrentes en la audiencia pública de la Villa 20, pues desde la "Mesa Activa por la Urbanización" se había organizado un empadronamiento propio, cuyo reconocimiento lucharon porque fuera incluido en la ley, aunque sin resultado favorable. Junto con esta consideración de los inquilinos como sujetos de derecho se sentaba precedente con que se incorporara el concepto de solución habitacional "única" (como una manera de desalentar la especulación inmobiliaria), el desglose de las familias, la simultaneidad de obras con la villa Olímpica y la construcción de equipamiento sanitario (como el postergado hospital Grierson) y educativo. Desde fines del año 2017, la formulación de las siguientes leyes se vio influenciada por estos reclamos.

\section{El proceso de formulación de la ley en Playón}

Entre todos los procesos de gestión participativa de las leyes de urbanización, el de Playón resultó el más conflictivo por las resistencias opuestas por los habitantes, que descreían sobre la índole de lo participativo. El proceso de formulación de la ley se extendió desde 
marzo hasta casi fines del año 2016 y tuvo tres instancias: una primera de debate con los miembros de la comisión, en la que se arribó a un borrador de proyecto de ley; una segunda de debate de ese borrador en el barrio en diferentes asambleas y una tercera, luego del ingreso de la ley en la Legislatura, de presentación y debate en todas las manzanas.

Durante la primera instancia la mesa de vecinos autoconvocados pugnó por una participación en el proceso, que le fue negada. En la segunda instancia, hubo fallas en la comunicación y difusión de los documentos y en la orientación de los debates, que llevaron a interminables reuniones deliberativas sin orientación ni sentido respecto de las decisiones. Los temas conflictivos fueron: el pedido de la eliminación del artículo 4 (presente en todas las leyes) respecto de que las decisiones en caso de no lograrse consenso las tomará el gobierno; la elevación del cupo de trabajadores del barrio en las obras al 30 \% (en lugar del $20 \%$ propuesto por el gobierno); el levantamiento de un nuevo censo de inquilinos y la eliminación de la zonificación en el plano por no haber sido nunca tratada. Finalmente desde el gobierno se decidió elevar el proyecto de ley a la Legislatura sin consenso, aduciendo urgencia de tiempos políticos y consecuente riesgo de pérdida de la partida presupuestaria asignada. Recién en la tercera y última etapa, desde el IVC, se organizó apropiadamente la difusión por temas y sectorizado por manzanas, pues desde el gobierno se entendía el proceso participativo como una cuestión comunicativa de decisiones tomadas previamente.

Una vez aprobada la ley, a fines de marzo de 2017 comenzó a funcionar la Mesa de Gestión Participativa (MGP) y se formularon los protocolos de funcionamiento de dicha mesa y de los relevamientos socio-ambientales. Las tensiones sociales en el interior del espacio social del barrio, entre los grupos de vecinos oficialistas y los que se oponían a la índole del proceso del gobierno, eran irreversibles, a tal punto que para los aspectos decisionales de la MGP se optó por la formación de consensos, para evitar enfrentamientos de los habitantes en las votaciones.

Desde el gobierno, se planteó que la MGP se abocaría prioritariamente al debate en torno a las “viviendas nuevas", si bien todo el año este debate estuvo tensionado por la solución de los problemas de los servicios de infraestructuras y las emergencias. Al hacerse cargo el IVC de las infraestructuras, sus intervenciones fueron erráticas, sin una programación coherente y sobre un sustrato de desconocimiento total de la situación existente del barrio, a tal punto que la situación sanitaria fue empeorando. La villa quedó arrasada, con problemas 
10. La carencia de personal idóneo en infraestructuras de villas fue un problema de arrastre desde fines del año 2016 y durante todo 2017 en Playón de Chacarita y en las demás villas (ver CLIC ET ÀL.

2017) en la provisión de agua en amplios sectores, y también con los desagües cloacales y pluviales. ${ }^{10}$ Entretanto, entre los habitantes sobrevolaba cierto imaginario que nunca se cumplió de construcción de infraestructuras definitivas simultáneamente a la construcción de las "viviendas nuevas". Durante el año 2018 la MGP se abocó a la elaboración del protocolo de los talleres de debate y a la definición de las trazas de las calles Palpa y Guevara, que completarían el proceso de integración urbana al barrio.

\section{Las "viviendas nuevas"}

El diseño de "viviendas nuevas" se vio condicionado por el plano de la ley que dividía el predio en cuatro manzanas que daban cuatro conjuntos habitacionales. A lo largo del año 2017, el proceso de diseño resultó sumamente complejo, porque en las mesas participativas se presentaron tres proyectos, con infinidad de modificaciones, pero con graves problemas de diseño. Esta situación fue abonando un creciente espíritu de desconcierto y desconfianza respecto de los técnicos del IVC y el gobierno.

El primer proyecto surgió de la reformulación de uno anterior gestado a partir de un convenio del gobierno con la FADU-UBA. La tipología edilicia adoptada en las manzanas 1, 2 y 3 era claustral, cuyos patios divididos por tiras transversales y a su vez en consorcios por paredes diagonales funcionarían como estacionamientos de automóviles (figura 1). En estas concepciones, la administración consorcial guiaba las decisiones proyectuales cruciales y condicionaba la espacialidad y la habitabilidad de estos espacios, y fue rotundamente rechazado por los técnicos asesores y la mayoría de los habitantes presentes. Las alturas homogéneas de las tiras de viviendas, además, hacían oscuros e inhabitables los patios, convirtiéndolos en espacios residuales de muy baja calidad ambiental, solo susceptibles de ser usados como depósitos y basurales. Otra cuestión grave era que existían infinidad de tipos de viviendas, cuya mayoría presentaba insalvables problemas funcionales y de superficies. En síntesis, era un proyecto que no resistía ningún tipo de valoración positiva ni desde el punto de vista proyectual, ni tampoco desde la habitabilidad. Lo único que persistió en todas las versiones de los diferentes proyectos fue la imagen ladrillera tradicional, argumentándose desde el IVC que no requería mantenimiento. Los habitantes, por la experiencia recogida en otros barrios, lograron imponer que el sistema constructivo fuera tradicional también en los interiores. 
Los conjuntos habitacionales en los procesos de "integración socio-urbana":

los casos de Playón de Chacarita y barrio Padre Carlos Mugica

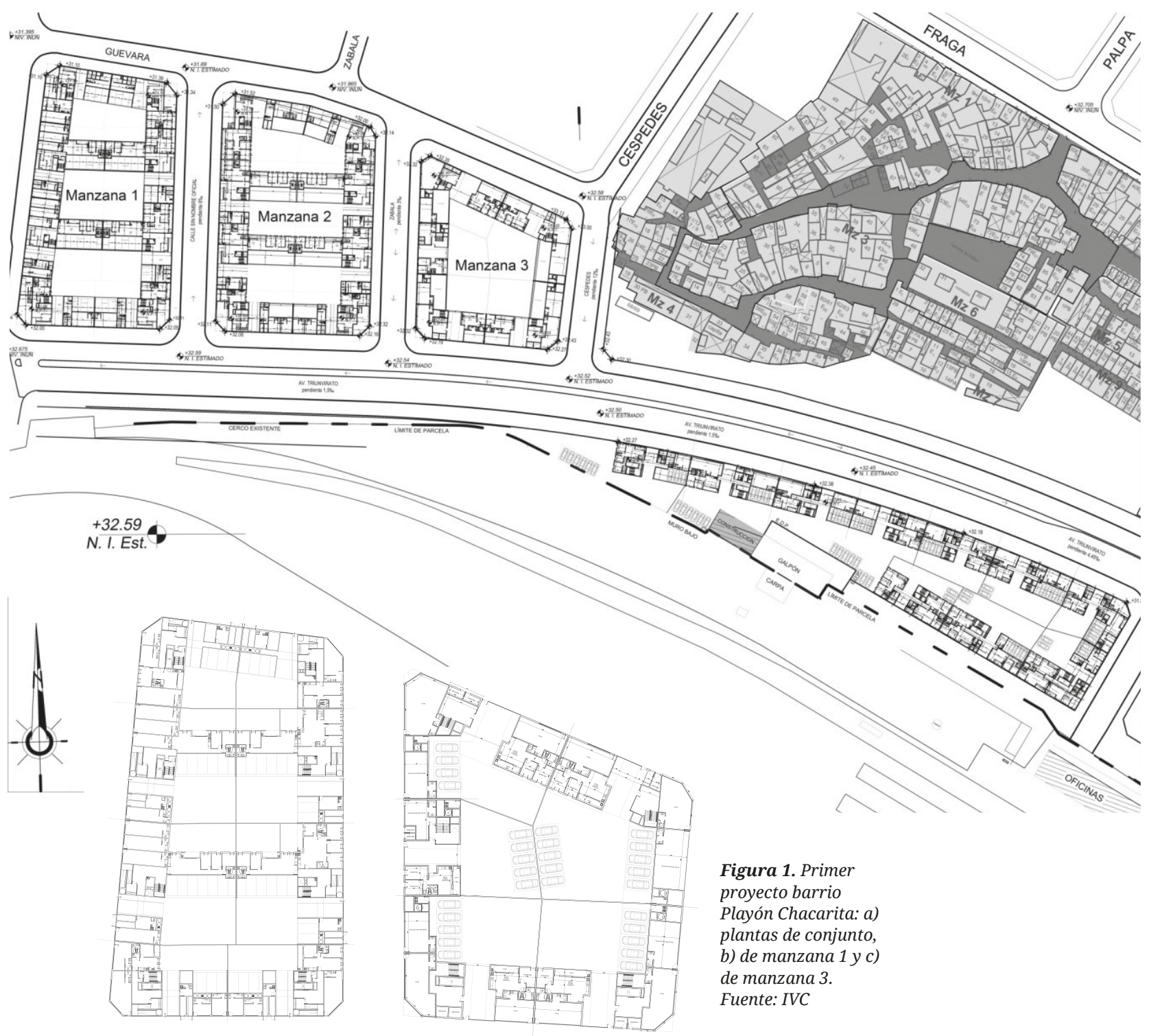


Figura 2. Segundo proyecto barrio Playón Chacarita: a) vista aérea y b) de conjunto. Fuente: IVC

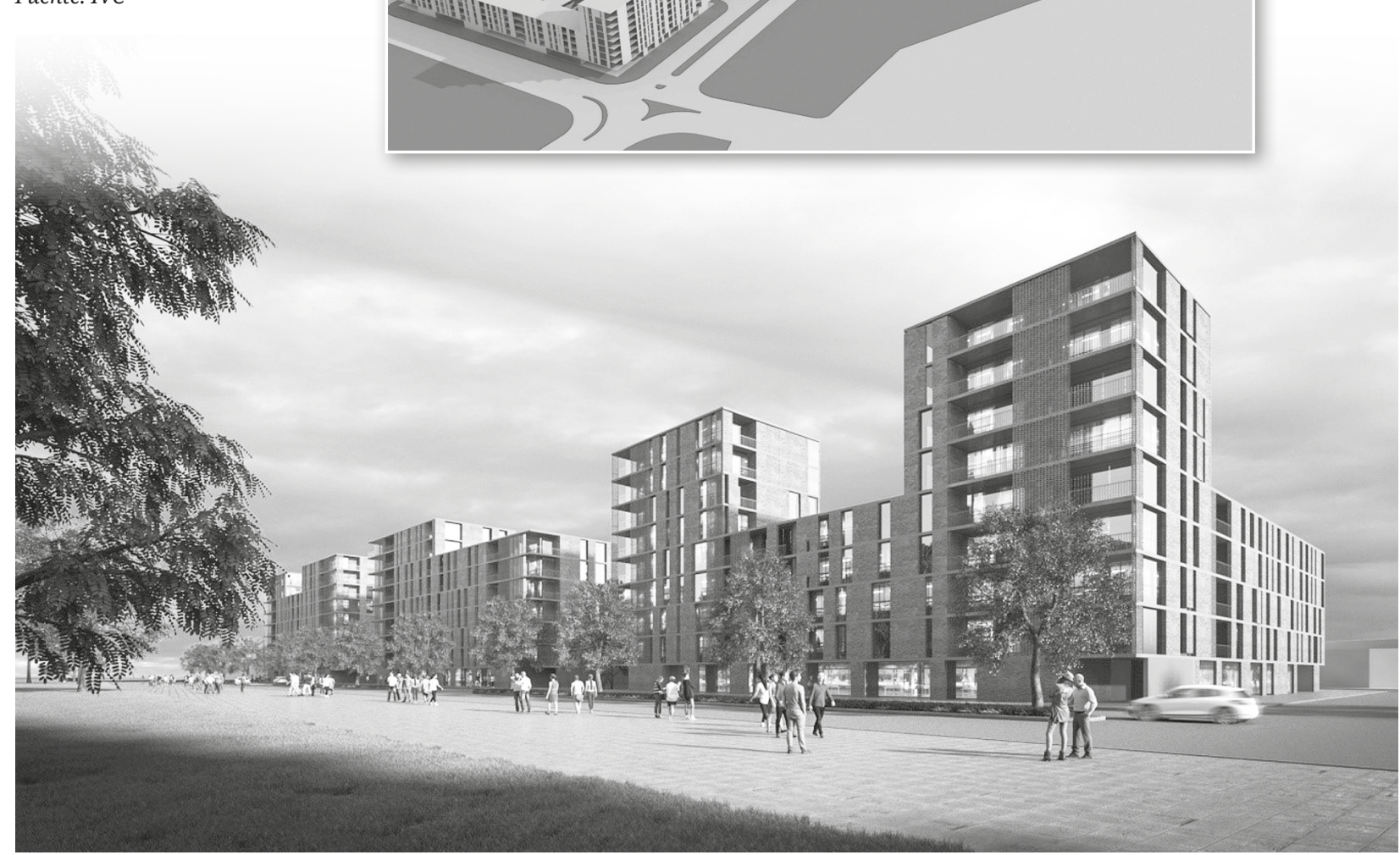


A mediados del año 2017, desde la MGP se propuso entonces localizar los estacionamientos en dársenas de las calles transversales, bajar las alturas de los conjuntos habitacionales y eliminar las divisiones internas de los patios para que fueran espacios de expansión. En este segundo proyecto se vieron reflejados parcialmente los cambios propuestos. En las calles transversales se propuso una altura de planta baja más cuatro pisos (con dúplex en los dos últimos), si bien no se aceptó bajar las alturas de los bloques sobre la avenida Triunvirato, en la que se arribó a una altura máxima de diez pisos, conforme con el nuevo Código Urbanístico. El perfil sobre esta avenida, en este nuevo proyecto, resultó caótico en cuanto a los saltos de alturas entre los bloques (figura 2). Además, las viviendas seguían teniendo los mismos graves problemas proyectuales (figura 3). A lo largo de las sucesivas versiones se consensuó la eliminación del ascensor en las tiras bajas para disminuir el costo de las expensas, y se arribó a que los patios fueran espacios públicos de dominio privado, cuyo mantenimiento estaría a cargo del gobierno.

Figura 3. Segundo proyecto Barrio Playón Chacarita: planta de conjunto. Fuente: IVC

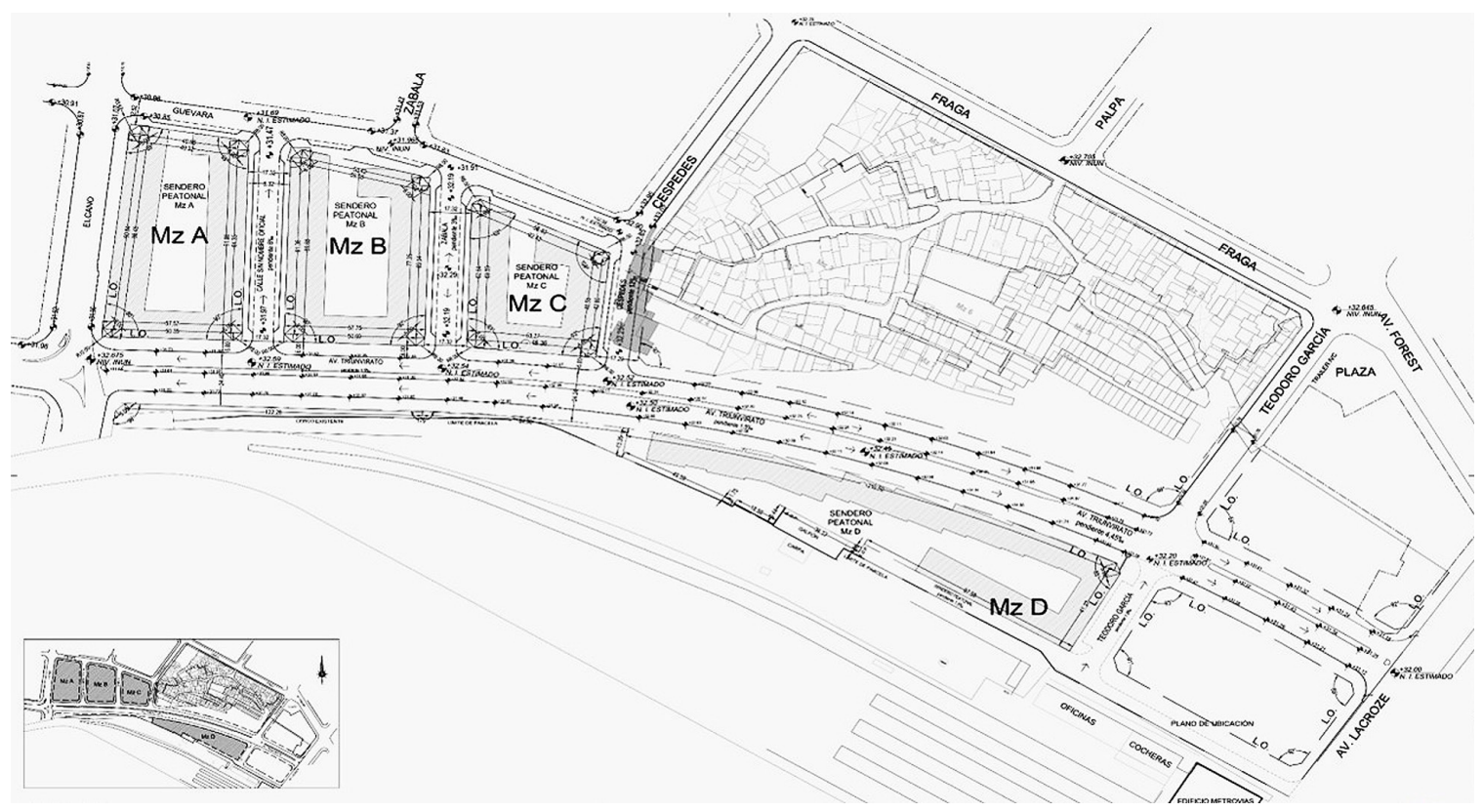


11. Ver el informe del $O D C$ 2017.
En síntesis, el proceso de formulación de las "viviendas nuevas" estuvo viciado desde los comienzos porque conforme con el proyecto que surgió del convenio con la FADU las dimensiones y proporciones de todas las manzanas daban como resultado más de una treintena de tipos de viviendas diferentes, con profundas inequidades en superficies, problemas graves funcionales y de orientaciones que fueron mejorando solo en algunos aspectos. Una objeción que introdujeron los habitantes y que tampoco tuvo recepción por parte del IVC fue la decisión de no tener balcones salientes. Se aducía que era una decisión proyectual y estructural, pero la realidad es que las plantas eran tan caóticas que resultaba imposible ordenarlas para dar una imagen viable de conjunto. Sí se logró la aprobación de la incorporación de ventilaciones forzadas en todas las cocinas (aunque finalmente no se adoptó), la consideración de terrazas comunes y que todos los dormitorios tuvieran placares y capacidad para dos camas.

Recién para la reunión de mesa técnica del 31 de agosto del año 2017 el proyecto estuvo en condiciones de comenzar a ser nuevamente analizado. Hasta entonces, las reuniones de mesas técnicas se habían limitado a "correcciones de diseño" asimilables a las del contexto académico universitario, con un proyecto destinado al fracaso, aunque se siguieron incorporando objeciones graves que el equipo técnico del IVC se comprometió a considerar. Aun así, desde el gobierno se decidió de manera unilateral presentarlo a licitación con la promesa de que las modificaciones se incorporarían una vez adjudicada la construcción, tal como se había procedido con Rodrigo Bueno. Esta decisión ilegítima, porque desoía los procesos participativos y decisionales establecidos por ley, desencadenó otra crisis en el proceso participativo. ${ }^{11}$

El proyecto de "viviendas nuevas" sujeto a licitación presentaba situaciones inequitativas en cuanto a superficie, distribución funcional y espacial, orientaciones y expansiones, que en su conjunto generarían graves problemas en el momento de la adjudicación y trasladarían los problemas de diseño a los costos. En la mesa técnica del 12 de octubre desde el IVC se blanqueó la dificultad de incorporar todas las modificaciones comprometidas, aduciendo problemas presupuestarios. Además se descubrió que las obras de infraestructuras para el barrio en marcha y las futuras planificadas serían para abastecer solamente a las viviendas nuevas, dejando al barrio desprotegido y sin solución a los problemas graves que históricamente siempre tuvo.

A fines del mes de noviembre, desde el gobierno se decidió cambiar el equipo técnico del IVC y se comenzó nuevamente con el proceso proyectual, con viviendas con tipología en U 
que respetaban el criterio de las alturas y no presentaban situaciones de inequidad en las superficies de las unidades habitacionales, si bien en las unidades de cuatro dormitorios la superficie de la cocina-comedor-living resultó proporcionalmente un tanto desajustada (figura 4). Las obras ya estaban adjudicadas y las empresas comenzaban con las excavaciones, sin tener el proyecto concluido ni los planos aprobados, y sin la participación de los habitantes.

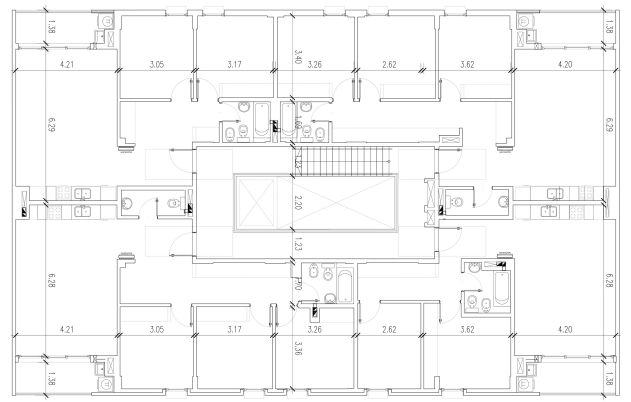

Figura 4. Tercer proyecto barrio Playón Chacarita: a) detalle de tipología y b) planta de conjunto. Fuente: IVC

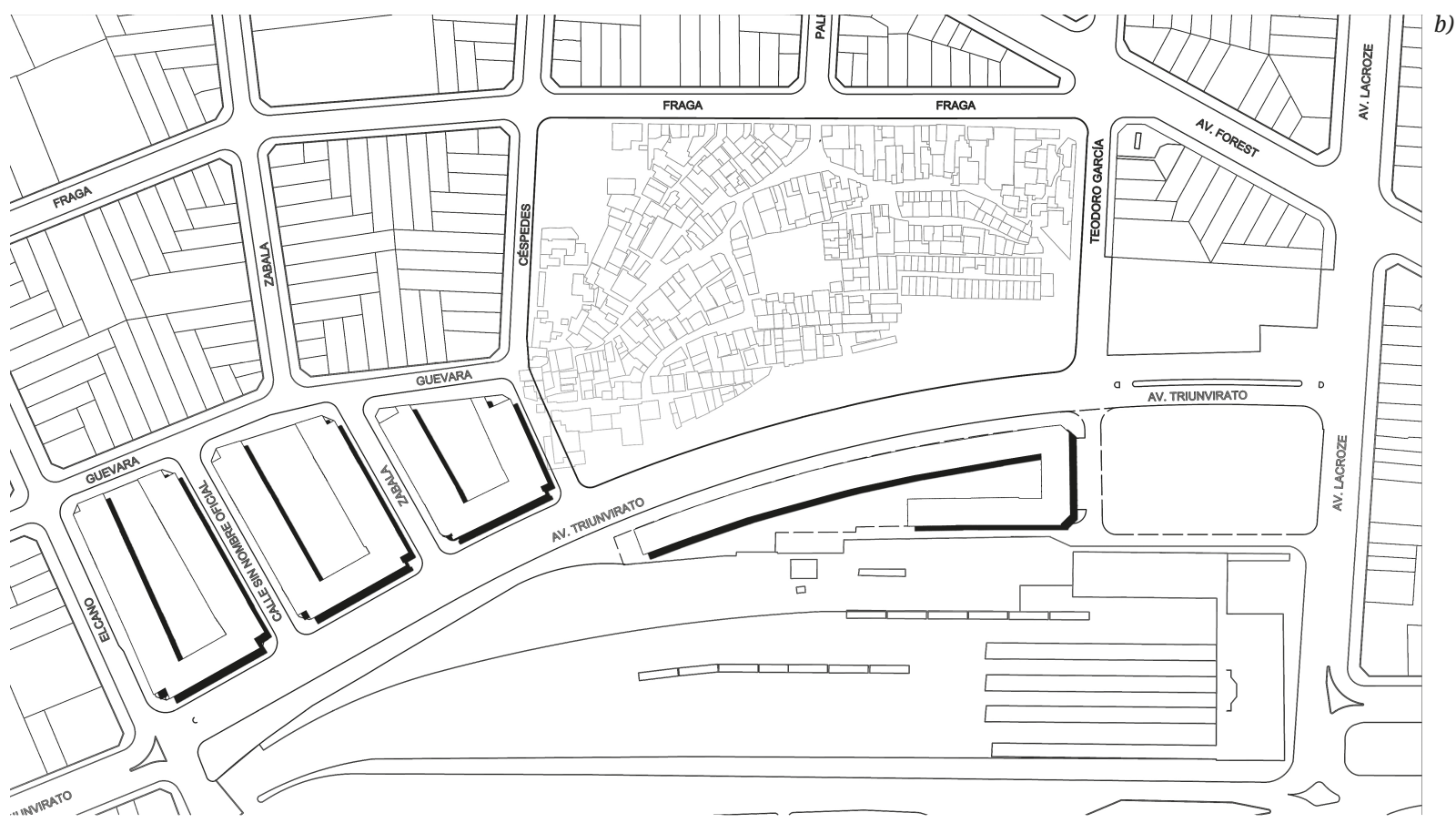


12. En el análisis de las intervenciones se retoma lo expuesto en el informe del ODC (SÁNCHEZ, BALDIVIEZO, 2017).

13. Los proyectos de viviendas tanto en el predio de Containera como en el Ex predio de YPF son fruto de un convenio entre la Facultad de Urbanismo, Diseño y Arquitectura de la Universidad de Buenos Aires y la SECISYU firmados en los años 2016 y 2017

\section{Los conjuntos habitacionales del barrio Mugica ${ }^{12}$}

En el año 2009, con la Ley 3343, el barrio Mugica fue el primero en lograr una ley participativa de urbanización. Pero al no tener un dictamen, la situación llevó a que desde entonces todas las decisiones en torno al proceso de urbanización no fueran consensuadas con los vecinos, comenzando por el desvío de la autopista Illia.

Si bien el aspecto habitacional del proceso incluía originalmente el acondicionamiento del $80 \%$ de las viviendas existentes, las soluciones habitacionales han sido poco menos que escasas o insignificantes. Se implementaron hasta el momento tres tipos de soluciones: el "Plan Piloto de mejoramiento", un conjunto habitacional conocido como Containera (hacia donde se realojaron las familias de Cristo Obrero por donde pasará la nueva traza de la autopista Illia) y su réplica la construcción 1200 viviendas en conjuntos de baja altura en los terrenos conocidos como "Ex predio de YPF". ${ }^{13}$ En la retórica del gobierno y de los proyectistas, Containera es el modelo paradigmático de gestión, tiene "una especial importancia por su segura incidencia en la gestión de las etapas sucesivas" y pretende ser "modélica" (UBA/ FADU/IEHu; GCABA, 2017: 14).

En el año 2017, la Secretaría de Integración Social y Urbana (SECISYU) reconoció que "de las 9900 viviendas y comercios que hay en la villa, unas 8500 requerirán algún grado de intervención”, y que en un año se darían por terminadas las obras (Musse, 2017). Entretanto, lo mismo se afirmó en materia de infraestructura, y como hasta el momento se acondicionó solo un 20 \%, se deduce que para el año 2019 habrán abordado el 80 \% que falta.

\section{El plan piloto de mejoramiento de viviendas}

Con el "Plan Piloto de Mejoramiento" se abordaron soluciones integrales de acondicionamiento de fachadas e interiores de 79 viviendas (y algunos comercios) de la Manzana G1 frente al playón lindante a la curva de la autopista Illia. Esta primera intervención, muy visible desde la autopista, se caracteriza por un sistema de rejas y escaleras caracol de acceso a las viviendas que anteponen una imagen homogénea de conjunto a las heterogéneas fachadas (figura 5). Aunque desde el gobierno se sostiene que "Uno de los objetivos finales de la integración socio-urbana de las villas, que se prevé finalizar para el 2019, es retirar aquellas escaleras endebles con las que quienes habitan en la villa acceden a sus hogares", 
"las nuevas estructuras metálicas presentadas cuentan con una baranda para evitar caídas" que solo "parecen más fuertes", dado que las normativas no permiten este tipo de escaleras en la ciudad (LN, 2017).

El acondicionamiento interior de las viviendas implica la solución de las condiciones de iluminación, ventilación, aislamiento, y en algunos casos de hacinamiento. Para ello, se contó equipos técnicos responsables a cargo de cada caso, liderados por un profesional arquitecto y otro de la rama social. El arquitecto proponía un proyecto de remodelación de la vivienda que una vez consensuado se construiría, previa firma del "acta de compromiso" de mantenimiento futuro por parte del propietario.
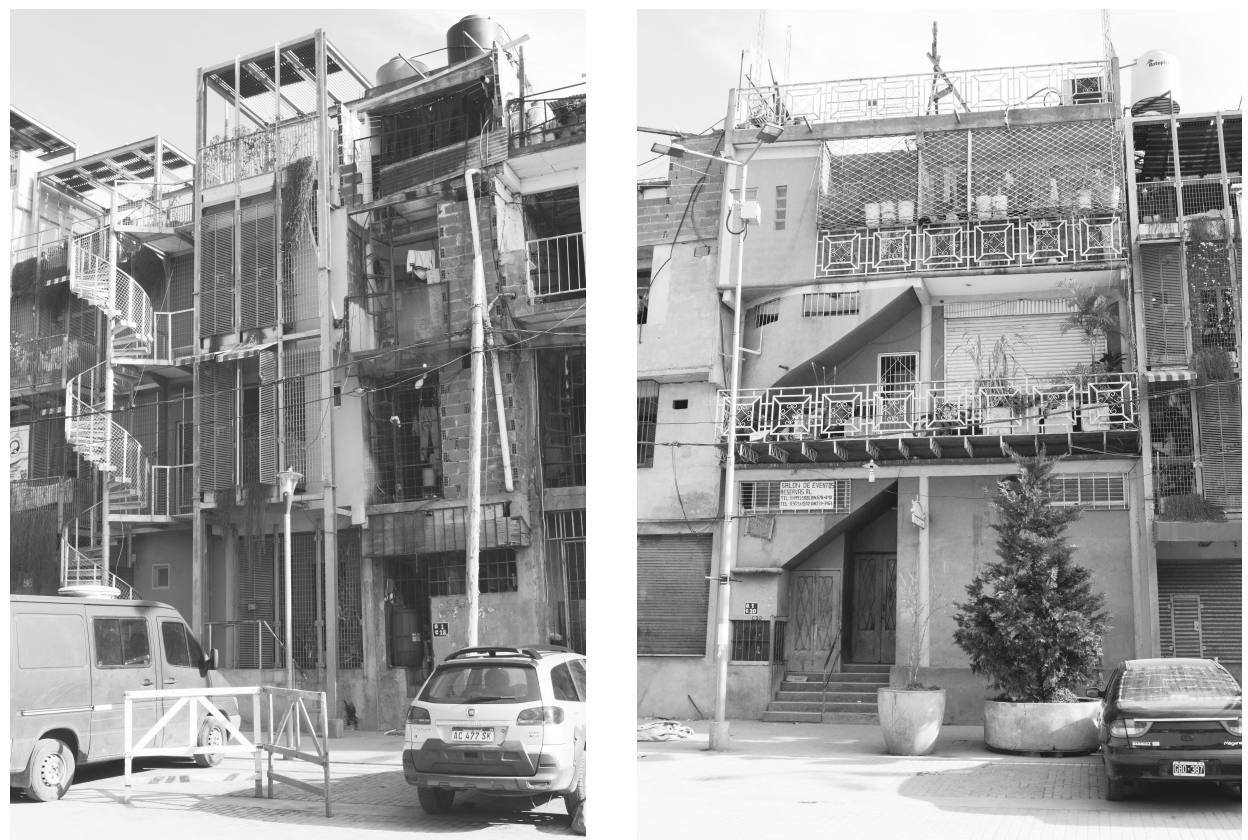

Figura 5. Plan Piloto de Mejoramiento Barrio Mugica: vista de las viviendas. Fuente: elaboración propia 
Los resultados de este plan piloto han sido desparejos. En muchos casos se detectan problemas de vicios de obra e ineficacia en los controles de ejecución: filtraciones de cañerías, problemas de aislaciones y de colocación del sistema de paneles internos, etc., pues el éxito de los resultados varía según las cooperativas de trabajo involucradas.

\section{Las viviendas Containera}

El conjunto habitacional Containera está destinado a los habitantes del sector de Cristo Obrero relocalizados con motivo del traslado de la autopista y tiene dos tipos de viviendas identificables con colores exteriores: las azules, que forman una tira de 40 viviendas y enfrentadas las verdes, con 80 viviendas. Las azules se construyeron primero y se habitaron en el año 2017, y las verdes están en proceso de adjudicación. Las tiras azules tienen tres niveles (planta baja y dos pisos) de viviendas de entre dos y cuatro dormitorios, separadas por los núcleos de escaleras, e incluyen ocho locales comerciales y un comedor en planta baja (figura 6). A las viviendas de planta baja se accede desde una galería exterior y tienen patios traseros como expansión (figura 7). Las plantas altas se expanden hacia los balcones, $\mathrm{y}$ las viviendas de las esquinas tienen balcones en dos direcciones.

El proceso de relocalización hacia Containera fue conflictivo y complejo, porque gran parte de las familias se rehusaban debido a que no estaban de acuerdo con el sistema constructivo, steel freaming, con los materiales empleados en la construcción (en particular el revestimiento de chapa que las asimilaba a conteiners), ni con el sistema de enrejados de los espacios semicubiertos que sentían opresivos y carcelarios (figura 8).

El sistema steel freaming fue implementado en Containera azul en todos los muros, exteriores, divisorios de viviendas e interiores. En cambio, en las verdes, las divisiones entre viviendas son de ladrillos de hormigón, que dan mayor privacidad a las viviendas en sus zonas de acceso, de manera que se eliminó el enjaulado continuo de los espacios semicubiertos (figura 9). El conjunto Containera azul está conformado por una tira simple de viviendas orientadas a ambos lados, mientras que las verdes están compuestas por una doble hilera de viviendas orientadas a ambos lados. En Containera verde se eliminaron los semicubiertos de planta baja que forman parte de los locales comerciales. Otros detalles de construcción diferencian a ambas en cuanto a la calidad. En las azules las losas son de hormigón pretensado, y en las verdes, postensado. Además las verdes tienen en los solados revestimiento 
Los conjuntos habitacionales en los procesos de "integración socio-urbana":

los casos de Playón de Chacarita y barrio Padre Carlos Mugica

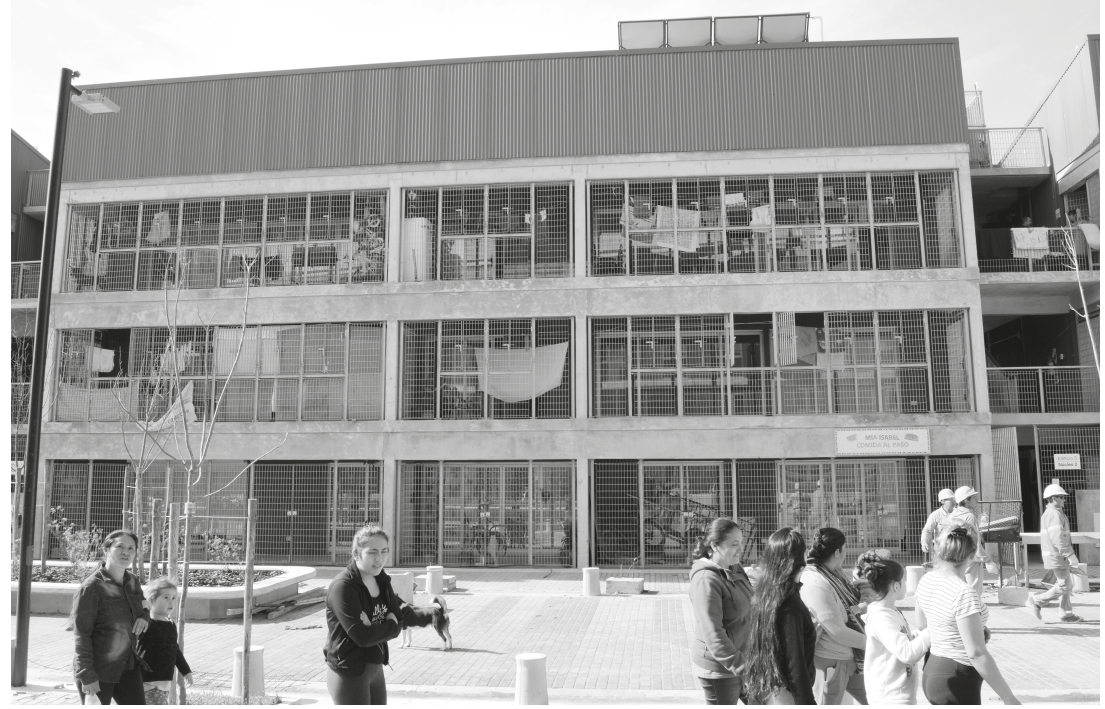

Figura 6.

Containera azul

barrio Mugica:

vistas.

Fuente:

elaboración

propia

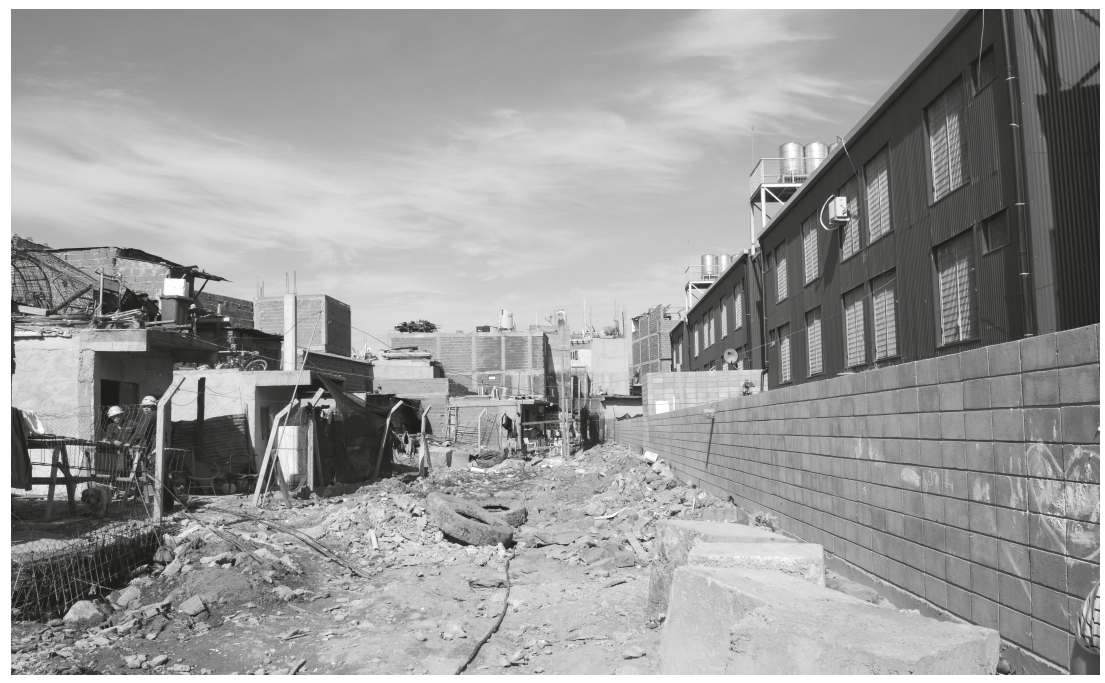

Figura

7.Containera

azul, barrio

Mugica: vistas

del patio trasero.

Fuente:

elaboración

propia 

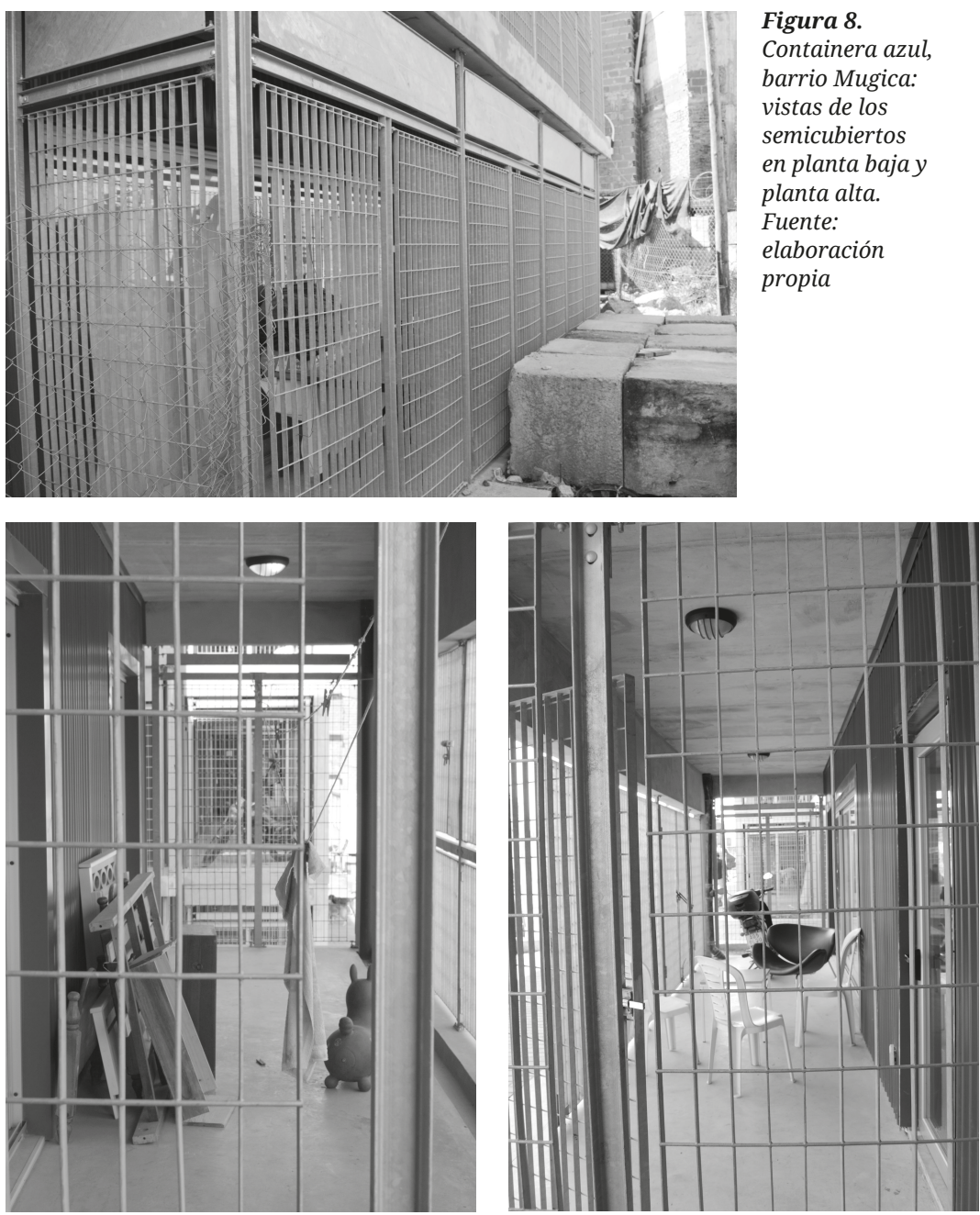

cerámico que los vecinos entienden como una terminación de mejor calidad frente al cemento alisado de las azules.

En las nuevas viviendas del sector YPF, para los núcleos húmedos y divisiones internas también se emplearon bloques de hormigón, mientras que en el exterior se sigue conservando el steel framing, aunque los habitantes consideran esto peligroso porque entienden que no frena las balas, ya que ese sector es uno de los más conflictivos del barrio.

Containera azul presenta problemas derivados de la falta de control de final de obra que redundan en filtraciones en los núcleos húmedos y problemas de dimensionamiento de los circuitos de electricidad que limitan el número de artefactos encendidos. Si bien estos problemas no son irreversibles, si no se remedian (hay suficiente experiencia en los conjuntos habitacionales de toda la ciudad en franco proceso de deterioro), pueden terminar siendo crónicos. Además, generaron entre los habitantes un sustrato de 


\section{Los conjuntos habitacionales en los procesos de "integración socio-urbana":}

los casos de Playón de Chacarita y barrio Padre Carlos Mugica

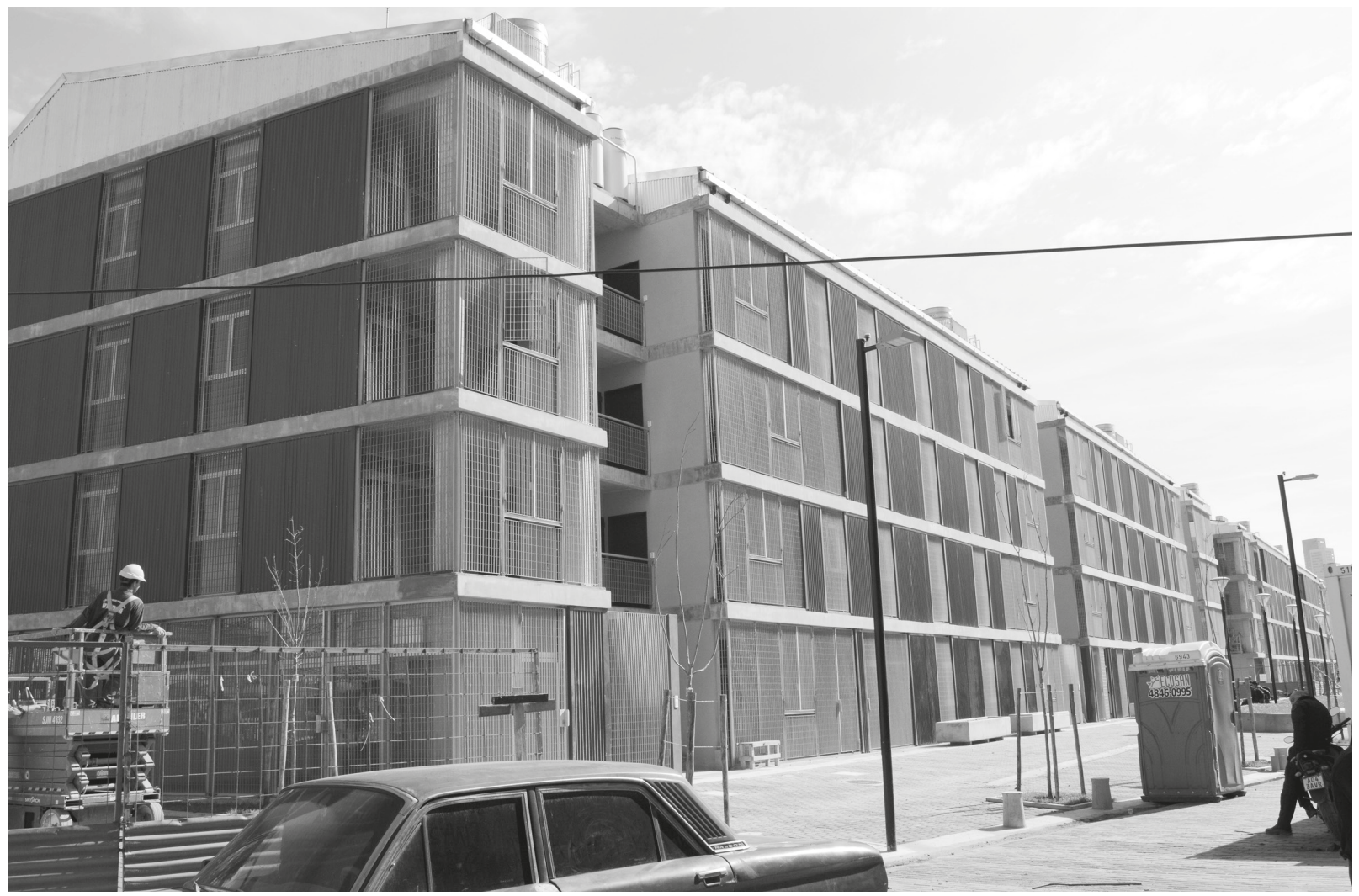

desconfianza sobre la calidad constructiva de todos los edificios. Los problemas más graves Figura 9. Containera verde, barrio Mugica: vistas. de diseño de las azules se meFuente: elaboración propia joraron en las verdes, en una suerte de prueba y error. 
14. $\operatorname{Ver} O D C, 2016$.

15. En las versiones más recientes se establecen excepciones para los que tengan ingresos asimilables a la canasta básica familiar.
El proceso de relocalización de los habitantes en Containera azul acusó desde los comienzos un balance desfavorable, pues además gran parte de las familias vieron profundamente socavados sus medios de vida. La mayoría sustentaba su economía con actividades comerciales diversas, y al ser relocalizadas perdieron anclaje territorial y gran parte de la clientela, y se encuentran marginados y con dificultades de accesibilidad respecto del resto del barrio.

Si bien ya en la Ley 3343 se puntualizaba en la necesidad de un trabajo previo que garantice la participación de los involucrados en todas las etapas del proceso, desde la "planificación", el "diseño de las viviendas", los "espacios comunes" y el "asesoramiento en el uso de las instalaciones" hasta la logística de la mudanza, muchos aspectos de estas "buenas prácticas" han sido desoídos, cuando no violentados en el caso de Containera, que es la muestra de las concepciones de un proceso de gestión que no fue participativo ni consensuado, y en el que no se tomaron medidas para resguardar las necesidades más básicas, como los medios de subsistencia.

\section{La formulación del dictamen de la ley}

Por no tener un dictamen el barrio, desde la sanción de la Ley 3343, las decisiones que el gobierno fue tomando respecto de las modificaciones del Proyecto Urbano original, cantidad, densidad, tipo y calidad de los conjuntos habitacionales (y de viviendas) que construir, el traslado de la traza de la autopista Illia y la cesión de tierras al BID para que construya un edificio (por sobre las vías del ferrocarril frente a la Facultad de Derecho) fueron tomadas unilateralmente, sin consulta ni consenso de los vecinos. ${ }^{14}$ En el contexto de este complejo escenario, desde el gobierno se lanzó a fines del año 2017 el proceso de elaboración del Dictamen de la Ley 3343, que paradójicamente se montó sobre la base de la formulación de un nuevo proyecto que desestimaba las cuestiones nodales que en esta ley se habían establecido.

Desde las primeras versiones del dictamen se reflejaron todas las inequidades posibles, pues en sí, la propuesta de gobierno implicaba condiciones regresivas respecto del resto de las villas y de la Ley 3343. La propuesta de gobierno consistía originalmente en que los vecinos pagaran por la tierra y por los gastos de escrituración, cuestión que no se planteaba en el resto de las villas. Actualmente se eliminaron los gastos de escrituración, pero se mantiene la condición del pago por la tierra. También se establecía en el proyecto de dictamen del gobierno que las cuotas de los créditos no debían superar el $20 \%$ de los ingresos familiares, cuando en la Ley 3343 estaba establecido que no debían superar el $15 \% .{ }^{15}$ Finalmente, 
mientras todas las villas cuentan con una MGP, en el barrio Mugica se siguió proponiendo la obsoleta figura de Consejo Consultivo (CC) con carácter colaborativo y no decisional en las cuestiones del barrio. El CC estará formado solo por los consejeros del barrio, y además, por su carácter "colaborativo", no tendrá alcances decisionales; solamente presenta restringidas atribuciones destinadas a "solicitar informes" y "fomentar y acompañar la participación activa de los/las vecinos/vecinas... solicitar la participación en carácter colaborativo y de asesoramiento a organizaciones gubernamentales y no gubernamentales especialistas en materias específicas afines al proyecto". Además, como en todos los proyectos de ley de todos los barrios, el gobierno se reserva el artículo que señala que en caso de no arribarse al consenso es el gobierno el que decide (en este caso es el artículo 10) (GCABA, 2018c: 4).

Entre las medidas tomadas que se desentienden de la Ley 3343 cuenta el desalojo violento de una familia que no quería ser relocalizada por no estar de acuerdo con la solución habitacional que le ofrecían. Además, se crea una "Comisión de Coordinación Institucional para la Gestión del Proceso de reurbanización” formada por un representante de la SECISYU, un representante de la Agencia de Administración de Bienes del Estado y el presidente del CC, que será elegido entre los consejeros, destinada a coordinar acciones entre el Estado Nacional y el GCABA que garanticen "el cumplimiento de los objetivos de la Ley 3343". Es decir que se genera una estructura burocrática que no garantiza la participación sino mediatizada, en la que no se evidencia el poder decisional de los habitantes, y que no garantiza una estructura participativa.

En el artículo 28 se dispone que la autoridad de aplicación "realizará las gestiones" ante las empresas prestatarias de los servicios públicos, "a fin de posibilitar el acceso a reducciones tarifarias suficientes”, y no garantiza que efectivamente sean tarifas sociales y reducidas, acordes con los ingresos de los habitantes.

Una de las cuestiones más controvertidas de la ley es el artículo 52, en el que se dispone la libre ocupación del espacio aéreo por parte del GCABA:

el GCBA podrá acceder a los metros cuadrados edificables para sobre elevar o sub-edificar lo existente, hasta el límite previsto en la normativa urbanística vigente al momento, lo cual se materializará en la primera escritura traslativa del dominio mediante una cesión de derechos, sobre los metros edificables. (GCABA, 2018c: 9) 
Esto implica que los derechos sobre la propiedad estarán restringidos y no podrán disponer la expansión de las construcciones en altura. Esta disposición, además alentada por el gobierno bajo "una política de incentivos", puede significar la pieza clave del proceso de transformación que acelerará el proceso de valorización y consecuentemente, de gentrificación. Otra inequidad respecto de los demás barrios consiste en las cargas a favor del proceso de urbanización que ningún barrio tiene.

En este barrio el proceso de desprendimiento de tierras destinadas a la urbanización se operativizó a través de la introducción de mecanismos normativos que invalidaban lo establecido en la Ley 3343. El 26 de diciembre de 2016, la SECISYU dictó la Resolución 208/2016, que aprobó el Subprograma de Cesión de Derechos Posesorios sobre Construcción de la Villa 31 y 31 Bis y San Martín. Por medio de este subprograma, los poseedores de inmuebles afectados cederían los derechos posesorios sobre su vivienda al GCBA, a cambio de un monto de dinero, algo expresamente prohibido en el artículo 9 de la Ley 3343 (Baldiviezo, 2017). A esto se suma el intento del gobierno, en noviembre de 2017, de la venta privada de una manzana del barrio que estaba destinada para uso habitacional en el predio de Flechabus, pero que por las luchas del barrio fue revertida.

El dictamen ofrece situaciones inequitativas respecto de otros barrios: dispone medidas tendientes a desafectar las tierras para uso de vivienda (artículo 56) y está directamente orientado a que los habitantes paguen por la tierra y por la capacidad constructiva potencial que establece la normativa (artículo 59). Todo esto en conjunto tiene como objetivo promover la valorización de las tierras, limitar el acceso a los habitantes y promover la gentrificación (GCABA, 2018c: 10). La introducción de lógicas productivas y económicas foráneas, alentadas en la ley, también operará indefectiblemente en desmedro de las economías locales.

\section{Consideraciones finales}

Los procesos participativos en el diseño de los conjuntos fueron muy conflictivos, y evidencian los problemas disciplinares para interpretar y dar respuesta a las necesidades de los habitantes y para insertarse en una política de integración socio-urbana inequitativa e inconsistente, cuyos objetivos, finalidades y criterios de "integración" difieren para cada 
barrio. En los conjuntos habitacionales de Playón se eligió un sistema constructivo tradicional y una imagen exterior ladrillera que no necesitaba mantenimiento. En el barrio Mugica, por el contrario, el rápido sistema constructivo requiere mantenimiento, ya está mostrando signos de deterioro, pero es de muy fácil remoción. A diferencia de Playón, en este caso ha sido planificado con un criterio de obsolescencia programada.

Los procesos participativos llevados adelante por el gobierno constituyen estereotipos foráneos acerca de la participación, orientados, en el mejor de los casos, a comunicar y legitimar las acciones de gobierno. Operan además como mecanismos de erosión de la voluntad participativa, pues las decisiones nodales se las reserva el gobierno.

En ninguna de las leyes se incorporaron herramientas urbanísticas para impedir la presión inmobiliaria, garantizar la integración social y urbana a largo plazo, dificultar procesos de gentrificación, posibilitar la captura de plusvalía e impedir que el suelo público se incorpore al mercado con criterios especulativos. La integración que se propone es de las tierras de las villas al mercado y a la especulación inmobiliaria; hacia allí se orientan todos los procesos.

\section{Abreviaturas y siglas}

ACIJ: Asociación Civil por la Igualdad y la Justicia.

CC: Consejo Consultivo.

CLIC: Cátedra Libre de Ingeniería Comunitaria.

DG: Defensoría General.

GCABA: Gobierno de la Ciudad Autónoma de Buenos Aires.

IP: iProfesional.

LN: La Nación.

MGP: Mesa de Gestión Participativa.

NU: Noticias Urbanas.

ODC: Observatorio del Derecho a la Ciudad.

SECISYU: Secretaría de Integración Social y Urbana.

T: Télam. 


\section{Bibliografía}

ARMANDO , Franco y KOUTSOVITIS, Eva (2016). "Las villas de la ciudad solicitan ser incorporadas al área de prestación de AYSA”, 5/2016. Extraído de: http://observatoriociudad. org/?s=noticia\&n=69.

ACIJ (2016). “Acuerdo por la Urbanización de las Villas”. En ACIJ 6/10/2016. Extraído de https://acij.org.ar/acuerdo-por-la-urbanizacion-de-las-villas/.

BALDIVIEZO, Jonatan Emanuel (2014). "Ilegalidades del GCBA en la entrega de títulos de propiedad en las villas: Primero la integración socio-urbana del barrio Los Piletones, luego la escrituración”, 27/10/2014. Extraído de http://observatoriociudad.org/?s=noticia\&n=25.

BALDIVIEZO, Jonatan Emanuel (2016). "Informe Técnico Infraestructura Barrio Piletones”, 19/12/2016. Extraído de http://observatoriociudad.org/?s=noticia\&n=108.

BALDIVIEZO, Jonatan Emanuel (2017). "Mitos de los procesos de urbanización de villas de Larreta. El GCBA quiere evitar que las familias tengan acceso a una vivienda en la Villa 31 y fortalece la especulación”. 3/2/2017. Extraído de http://observatoriociudad.org/?s=noticia\&n=109.

BALDIVIEZO, Jonatan Emanuel (2017a). "El PRO vendería al Grupo América (Vila-Manzano) las tierras conocidas como Flechabus cambiando su destino de viviendas para las familias del Barrio Carlos Mugica (ex Villa 31)”. 29/11/2017. Extraído de http://observatoriociudad.org/?s=noticia\&n=164.

BLONDIAUX, Loic (2008) El nuevo espíritu de la democracia. Actualidad de la democracia participativa. Prometeo, Buenos Aires.

BOIRA, Josep Vicent (2014). "Presentación”. En Edward W. Soja. En busca de la justicia espacial, Valenci, Tirant Humanidades.

CASTRO, Ángeles (2010). "Villa 31: ingresan materiales ilegalmente” En La Nación 25/1/2010. Buenos Aires.

CLIC; ODC; FSH; IPYPP (2017). “Consideraciones y propuestas para fortalecer los procesos de re-urbanización e integración socio-urbana de las villas de la CABA en relación con la regularización y acceso a los servicios públicos”. 3/3/2017. Extraído de http://observatoriociudad.org/?s=noticia\&n=119.

CLIC; ODC; CTAA-FSH; CTAA-MVBGA; Mónica Ruejas (2017). "Mitos de los procesos de urbanización de villas de Larreta: $2^{\circ}$ Mito 'Los servicios públicos serán iguales que en el resto de la ciudad”. 15/2/2017. Extraído de: http://observatoriociudad.org/?s=noticia\&n=111.

DE CERTEAU, Michel; GIARD, Luce; MAYOL, Pierre (1994) La invención de lo cotidiano 2. Habitar, cocinar. Universidad Iberoamericana, Biblioteca Francisco Xavier Clavigero, México, 2006. 
DEL RÍo, Juan Pablo (2015). "La vivienda social y la cuestión urbana. Consideraciones teóricas para el análisis de las políticas del hábitat”. Estudios del Hábitat Volumen 13, 1 7/2015, Buenos Aires: Facultad de Arquitectura y Urbanismo de la Universidad Nacional de La Plata, 76-92. Extraído de https://revistas.unlp.edu.ar/Habitat/article/view/2247.

DG (2008). "Dossier de prensa. Desarrollo del conflicto en torno a la Villa 31". 11/2008. Extraído de https://www.mpdefensa.gob.ar/attachments/976_dossier\%20villa\%2031.pdf.

DUSSEL, E. (2006) 20 tesis sobre política (2. ${ }^{a}$ ed.). Siglo XXI-CREFAL, México.

GARNIER, Jean Pierre (2012). "El derecho a la ciudad desde Henri Lefebvre hasta David Harvey. Entre teorizaciones y realización”. En Ciudades 15 (1), Instituto Universitario de Urbanística, Valladolid, 217-225. Extraído de https://revistas.uva.es/index.php/ciudades/ article/view/1157/991.

GCABA (2018). "Playón de Chacarita”. Extraído de http://www.buenosaires.gob.ar/ institutodevivienda/integracion-de-los-barrios/playon-de-chacarita.

GCABA (2018b). "Barrio 31”. Secretaría de Integración Social y Urbana, Buenos Aires. Extraído de http://www.buenosaires.gob.ar/sites/gcaba/files/presentacion_institucional.pdf.

GCABA (2018c) Proyecto de Ley 2019-41-AJG. E.E. 25637097-MGEYA_SECIYU/18, 18/9.

GUBER, Rosana (2004) El salvaje metropolitano. Reconstrucción del conocimiento social en el trabajo de campo. Paidós, Buenos Aires.

HAMMERSLEY, Martyn y ATKINSON, Paul (1994) Etnografía. Métodos de investigación. Editorial Paidós, Ciudad de Buenos Aires.

HALL, Peter (1988) Ciudades del mañana. Historia del urbanismo en el siglo XX. Ediciones del Serbal, Barcelona, 1996.

HARVEY, David (2012) Ciudades rebeldes. Del derecho a la ciudad a la revolución urbana. Akal, Salamanca, 2013.

IPROFESIONAL (2016). "Plan de Urbanización en la Villa 31: los vecinos tendrán que pedir permiso para ingresar materiales de construcción”. En iProfesional 28/9/2016. Extraído de https://www.iprofesional.com/actualidad/239308-construcci\%C3\%B3n-permiso-villa-31-Plan-de-Urbanizacion-en-la-Villa-31-los-vecinos-tendran-que-pedir-permiso-para-ingresar-materiales-de-construccion.

LA NACIÓN (2007). "Erigen un muro para contener a la Villa 31”. En La Nación 10/1/2007. Ciudad de Buenos Aires.

LA NACIÓN (2008). “Advierten sobre riesgos 'catastróficos' en las viviendas precarias de Retiro”. En: La Nación 9/6/2008. Ciudad de Buenos Aires.

LEFEBVRE, Henri (1968) El derecho a la ciudad. Península, Barcelona, 1973. 
LEFEBVRE, Henri (2074) La producción del espacio. Capitán Swing, Madrid, 2013.

MACRI, Mauricio (2016). "Buenos Aires mira al sur”. En De villa a Barrio 2012-2015. Gobierno de la Ciudad Autónoma de Buenos Aires, Buenos Aires, 10.

MAINGUENEAU, Dominique (1976) Introducción a los métodos de análisis del discurso. Hachette, Buenos Aires, 1989.

MARTÍNEZ, Rubén (2016) Versión Taquigráfica. Audiencia Pública. Reurbanización, zonificación e integración socio-urbana de la Villa 20, en el marco de la Ley 1770. Dirección General de Taquígrafos, Ciudad de Buenos Aires.

MUSSE, Valeria (2017). "En la villa 31-31 bis, los vecinos disfrutan de las primeras casas refaccionadas". En La Nación 20/4/2018. Ciudad de Buenos Aires.

NAVIA, Javier y CASTRO, Ángeles (2008). "Macri analiza llamar a un plebiscito sobre la urbanización de villas”. En La Nación 8/6/2008. Ciudad de Buenos Aires.

NU (2016). "Larreta anunció un plan de urbanización para la Villa 31". 10/8/2016. Ciudad de Buenos Aires. Extraído de http://www.noticiasurbanas.com.ar/?noticia=larreta-anuncioun-plan-de-urbanizacion-para-la-villa-31.

ODC (2016). "Mitos de los procesos de urbanización de villas de Larreta- El GCBA quiere evitar que las familias tengan acceso a una vivienda en la Villa 31 y fortalece la especulación". 3/2/2016. Ciudad de Buenos Aires. Extraído de: http://observatoriociudad.org/?s=noticia\&n=109. ODC (2016a). "Rechazo absoluto de los delegados y consejeros del Barrio Carlos Mugica (Ex Villa 31-31 bis)”. 29/11/2016. Ciudad de Buenos Aires. Extraído de: http:// observatoriociudad.org/?s=noticia\&n=100.

ODC (2017) "Nuevamente las villas de la ciudad inundadas". 21/2/2017. Ciudad de Buenos Aires. Extraído de http://observatoriociudad.org/?s=noticia\&n=112.

ODC (2017b). "El apresuramiento por los tiempos electorales lleva al GCBA a cometer los errores del pasado". 10/11/2017. Ciudad de Buenos Aires. Extraído de: http:// observatoriociudad.org/?s=noticia\&n=163.

ODC, CLIC (2018). "Larreta desaloja ilegalmente a familias del Barrio Carlos Mugica (Villa 31-31 bis)". 24/2/2018. Ciudad de Buenos Aires. Extraído de http://observatoriociudad. org/?s=noticia\&n=170. 
OSZLAK, Oscar y O'DONNELL, Guillermo (1995). "Estado y políticas estatales en América Latina: Hacia una estrategia de investigación”. En Redes, Vol. 2, Núm. 4. Universidad Nacional de Quilmes, Buenos Aires, 99-128. Extraído de http://www.redalyc.org/ pdf/907/90711285004.pdf.

PERFIL (2010). "Macri otorgará títulos de propiedad a los vecinos de las villas". En Perfil 5/12/2010. Ciudad de Buenos Aires.

RODRÍGUEZ LARRETA, Horacio (2016). "Articulación e integralidad". De villa a Barrio 2012-2015. Gobierno de la Ciudad Autónoma De Buenos Aires, Ciudad de Buenos Aires, 12.

SANCHEZ, Sandra Inés y BALDIVIEZO, Jonatan Emanuel (2018). "De las conclusiones del Informe Técnico-Estructural que justificó el desalojo forzoso y demolición de viviendas en Barrio Carlos Mugica (Ex Villa 31-31 bis) se desprende que el GCBA podría hacer lo mismo con cualquier vivienda construida en las villas de la ciudad" 3/3/2018. Ciudad de Buenos Aires. Extraído de http://observatoriociudad.org/panel/biblioteca/18_15_452018\%20-\%20 02\%20-\%20febrero\%20-\%2028\%20-\%20Desalojo\%20administrativo\%20ilegal\%20e \%20 infundado.pdf.

SIERRA, Fernando Nahuel (2016) Versión Taquigráfica. Audiencia Pública. Reurbanización, zonificación e integración socio-urbana de la Villa 20, en el marco de la Ley 1770. Dirección General de Taquígrafos, Buenos Aires.

TARBUCH, Laura y BALDIVIEZO, Jonatan Emanuel (2014). "Titularizar la precariedad no es integración urbana”. En Observatorio del Derecho a la Ciudad, Informe 27/10/2014. Ciudad de Buenos Aires. Extraído de:https://es.scribd.com/document/244579529/2014-10-octubre-27informe-TITULARIZAR-LA-PRECARIEDAD-NO-ES-INTEGRACION-URBANA-pdf\#from_embed. T (2009). "Limitan las construcciones en la Villa 31 y 31 bis". En Periódico Comuna 12 23/1/2009. Ciudad de Buenos Aires. Extraído de http://www.lacomuna12.com.ar/limitan-lasconstrucciones-en-la-villa-31-y-31-bis-3557.

WACQUANT, Loic (2001) Parias urbanos. Marginalidad en la ciudad a comienzos del milenio. Manantial, Ciudad de Buenos Aires.

WACQUANT, Loic (2007) Los condenados de la ciudad. Gueto, periferias y Estado. Siglo XXI, Ciudad de Buenos Aires. 
